\title{
QUEEN'S
UNIVERSITY
BELFAST
}

\section{In vitro antimicrobial activity of ceftolozane/tazobactam against $P$. aeruginosa and other non-fermenting gram-negative organisms in adults with cystic fibrosis}

Gramegna, A., Millar, B. C., Blasi, F., Elborn, J. S., Downey, D. G., \& Moore, J. E. (2018). In vitro antimicrobial activity of ceftolozane/tazobactam against $P$. aeruginosa and other non-fermenting gram-negative organisms in adults with cystic fibrosis. Journal of global antimicrobial resistance. https://doi.org/10.1016/j.jgar.2018.03.002

Published in:

Journal of global antimicrobial resistance

Document Version:

Peer reviewed version

Queen's University Belfast - Research Portal:

Link to publication record in Queen's University Belfast Research Portal

\section{Publisher rights}

Copyright 2018 Elsevier.

This manuscript is distributed under a Creative Commons Attribution-NonCommercial-NoDerivs License

(https://creativecommons.org/licenses/by-nc-nd/4.0/), which permits distribution and reproduction for non-commercial purposes, provided the author and source are cited

\section{General rights}

Copyright for the publications made accessible via the Queen's University Belfast Research Portal is retained by the author(s) and / or other copyright owners and it is a condition of accessing these publications that users recognise and abide by the legal requirements associated with these rights.

Take down policy

The Research Portal is Queen's institutional repository that provides access to Queen's research output. Every effort has been made to ensure that content in the Research Portal does not infringe any person's rights, or applicable UK laws. If you discover content in the

Research Portal that you believe breaches copyright or violates any law, please contact openaccess@qub.ac.uk. 


\section{Accepted Manuscript}

Title: IN VITRO ANTIMICROBIAL ACTIVITY OF CEFTOLOZANE/TAZOBACTAM AGAINST P. AERUGINOSA AND OTHER NON-FERMENTING GRAM-NEGATIVE ORGANISMS IN ADULTS WITH CYSTIC FIBROSIS

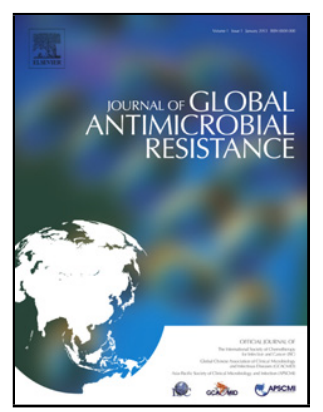

Authors: A. Gramegna, BC. Millar, F. Blasi, JS. Elborn, DG.

Downey, JE. Moore

PII: S2213-7165(18)30054-7

DOI: https://doi.org/10.1016/j.jgar.2018.03.002

Reference: JGAR 620

To appear in:

Received date: 7-9-2017

Revised date: $5-1-2018$

Accepted date: $10-3-2018$

Please cite this article as: A.Gramegna, BC.Millar, F.Blasi, JS.Elborn, DG.Downey, JE.Moore, IN VITRO ANTIMICROBIAL ACTIVITY OF CEFTOLOZANE/TAZOBACTAM AGAINST P.AERUGINOSA AND OTHER NON-FERMENTING GRAM-NEGATIVE ORGANISMS IN ADULTS WITH CYSTIC FIBROSIS (2010), https://doi.org/10.1016/j.jgar.2018.03.002

This is a PDF file of an unedited manuscript that has been accepted for publication. As a service to our customers we are providing this early version of the manuscript. The manuscript will undergo copyediting, typesetting, and review of the resulting proof before it is published in its final form. Please note that during the production process errors may be discovered which could affect the content, and all legal disclaimers that apply to the journal pertain. 


\title{
$\begin{array}{llll}\text { IN } & \text { VITRO ANTIMICROBIAL } & \text { ACTIVITY }\end{array}$ \\ CEFTOLOZANE/TAZOBACTAM AGAINST P. AERUGINOSA AND OTHER NON-FERMENTING GRAM-NEGATIVE ORGANISMS IN ADULTS WITH CYSTIC FIBROSIS
}

\author{
A. Gramegna 1,2*; BC. Millar 3,4; F. Blasi 1; JS. Elborn 5,6; DG. Downey 2,5; \\ JE. Moore 3,5
}

1. Department of Pathophysiology and Transplantation, Università degli Studi di Milano, Cardio-thoracic unit and Cystic Fibrosis Adult Center Fondazione IRCCS Ca' Granda Ospedale Maggiore Policlinico, Milan, Italy

2. Northern Ireland Regional Adult CF Unit, Belfast City Hospital, Belfast, UK

3. Northern Ireland Public Health Laboratory, Belfast City Hospital, Belfast, UK

4. School of Biomedical Sciences, Ulster University, Coleraine, UK

5. Centre for Experimental Medicine, Queen's University, Belfast, UK

6. Imperial College and Royal Brompton Hospital, London, UK;

\section{${ }^{\star}$ Corresponding author}

Dr Andrea Gramegna,

Department of Pathophysiology and Transplantation,

Università degli Studi di Milano,

Cardio-thoracic unit and Cystic Fibrosis Adult Center Fondazione IRCCS Ca' Granda Ospedale Maggiore Policlinico Milano

Milan

Italy 
Tel. +390255032503

Fax. +390255034150

Email: gramegnamed@gmail.com

\section{HIGHLIGHTS}

- A novel cephalosporin with activity towards non fermenting Gram-negative bacteria.

- Good in vitro antimicrobial activity against CF clinical isolates of P. aeruginosa in comparison to other antimicrobials.

- No activity against B. cenocepacia and $A$. xylosoxidans.

\section{ABSTRACT}

INTRODUCTION. Pulmonary exacerbations in people with Cystic Fibrosis (CF), with chronic Gram-negative pathogens, are associated with reduced survival. These pathogens are usually treated with repeated courses of systemic antibiotics. However there is a linked emergence of multidrug resistant (MDR) pathogens. Ceftolozane/tazobactam is a new cephalosporin/beta-lactamase inhibitor combination that has been demonstrated to have good activity against MDR Pseudomonas aeruginosa.

MATERIAL \& METHODS. In this study ceftolozane/tazobactam was compared to other commonly used intravenous antibiotics against 193 non-fermenting Gramnegative bacteria isolated from CF sputum specimens, including P. aeruginosa, Achromobacter xylosoxidans, Stenotrophomonas maltophilia and Burkholderia. MICs 
to ceftolozane/tazobactam were determined by standard E-test assay and interpreted according to current EUCAST guidelines.

RESULTS. Ceftolozane/tazobactam had good in vitro antimicrobial activity against CF clinical isolates of $\mathrm{P}$. aeruginosa in comparison to other antimicrobials with the exception of colistin. Ceftolozane/tazobactam also had activity against S. maltophilia, but was not active against B. cenocepacia and A. xylosoxidans.

DISCUSSION. ceftolozane/tazobactam showed excellent in vitro activity against $P$. aeruginosa from CF clinical isolates. This antibiotic is a potential therapeutic option when presented with challenging MDR $P$. aeruginosa and $S$. maltophilia exacerbations. Further clinical experience and trials in CF are required to determine the place of this antimicrobial in clinical practice.

KEYWORDS: Ceftolozane/tazobactam; P. aeruginosa; S. maltophilia; respiratory infection; cystic fibrosis; antibiotic resistance.

\section{INTRODUCTION}

Pulmonary exacerbations of chronic respiratory infections significantly contribute to the morbidity and mortality among adults with Cystic Fibrosis (CF) [1]. These infections are usually dominated by non-fermenting Gram-negative bacteria (NFGNB), e.g. Burkholderia cenocepacia, Achromobacter xylosoxidans, Stenotrophomonas maltophilia and especially Pseudomonas aeruginosa [2].

Aggressive antibiotic management of acute pulmonary exacerbations has contributed to improvements in the median expectation of life for adults affected by CF with a median predicted survival of 41 years [3]. However, the repeated use of antibiotics 
aligns with the emergence of antimicrobial resistance [4]. The persistence of MDR bacterial strains in the lung is associated with poorer clinical outcomes [3].

Ceftolozane/tazobactam is a new extended-spectrum beta-lactam/beta-lactamase inhibitor combination approved by the European Medicines Agency (EMA) for the treatment of complicated urinary and intra-abdominal infections in adults [5].

Ceftolozane has a similar mechanism of action to other cephalosporin antibiotics. The addition of tazobactam increases the activity of this combination to include several extended-spectrum beta-lactamase-producing bacteria [6]. This new compound has demonstrated promising results in comparison with other betalactams against $P$. aeruginosa strains with various resistance patterns in non-CF isolates [7]. The purpose of this study was to evaluate the in vitro antibacterial activity of ceftolozane/tazobactam against $P$. aeruginosa and other NF-GNB isolates from CF patients.

\section{METHODS}

This study was performed on an anonymized historical collection of non-duplicated bacterial isolates from patients with CF attending the Northern Ireland Regional Adult CF Centre, Belfast City Hospital, UK. One hundred and twenty P. aeruginosa isolates, 34 S. maltophilia isolates and 39 B. cenocepacia isolates were recovered from CF sputum specimens between January 2001 to December 2010 (www.microark.com). P. aeruginosa reference strain NCTC 10662 was also included. Minimum inhibitory concentration (MIC) to ceftolozane/tazobactam for each isolate was determined by standard E-test assay based on the manufacturer's recommendations [8]. The results were interpreted according to current EUCAST 
guidelines [9]. A clinical breakpoint of $4 \mathrm{mcg} / \mathrm{mL}$ was employed for $P$. aeruginosa. However as no species-specific breakpoint is currently available for other NF-GNB, the same breakpoint of $\leq 4 \mathrm{mcg} / \mathrm{mL}$ was used.

Susceptibilities for all others antimicrobials were determined by the modified BauerKirby disc diffusion methodology following the EUCAST criteria [9]. Comparator antimicrobials were piperacillin/tazobactam (30/6 mcg), aztreonam (30 mcg), ceftazidime (30 mcg), meropenem (10 mcg), ciprofloxacin (5 mcg), tobramycin (10 $\mathrm{mcg})$ and colistin $(10 \mathrm{mcg})$. Testing of trimethoprim/sulphamethoxazole $(25 \mathrm{mcg})$ and minocycline (30 $\mathrm{mcg})$ were added for $S$. maltophilia and B. cenocepacia isolates.

MDR was defined as acquired non-susceptibility to at least one agent in three or more antimicrobial classes, XDR was defined as susceptibility to only one or two categories and pan-Resistant was defined as non-susceptibility to all agents in all antimicrobial classes [10].

\section{RESULTS}

The median MIC for ceftolozane/tazobactam against $P$. aeruginosa was $1.5 \mathrm{mcg} / \mathrm{mL}$; $\mathrm{MIC}_{50}$ and $\mathrm{MIC}_{90}$ were $1.5 \mathrm{mcg} / \mathrm{mL}$ and $8 \mathrm{mcg} / \mathrm{mL}$, respectively. A total of $101 / 120$ (84.2\%) P. aeruginosa clinical isolates were sensitive to ceftolozane/tazobactam and in only two cases isolates were highly resistant (MIC >256). The percentage of resistant $P$. aeruginosa isolates for ceftolozane/tazobactam and other antimicrobial comparators is reported in Figure 1.

In this collection of strains, percentage of resistance for ceftolozane/tazobactam were lower than those for piperacillin/tazobactam, meropenem and aztreonam (Figure 1). In particular, ceftolozane/tazobactam was effective in most of meropenem-resistant P. aeruginosa isolates (20/34, median MIC 3). 
Ceftolozane/tazobactam median MICs were significantly higher in ceftazidime and meropenem resistant isolates in comparison to susceptible isolates $(p=0.003$ and 0.013 , respectively); in particular, the $57 / 71$ (80.3\%) ceftazidime-resistant isolates were sensitive to ceftolozane/tazobactam, whilst all the isolates resistant to ceftolozane/tazobactam $(n=14)$ were also resistant to ceftazidime. Antibiotic resistance among $P$. aeruginosa (defined as both MDR and XDR isolates) was observed in 51 isolates (42.5\%), while pan-resistant isolates were $3(2.5 \%)$.

Ceftolozane/tazobactam median MIC in P. aeruginosa isolates increased markedly as the number of resistant antibiotic classes increased (Table 1).

The median MIC for ceftolozane/tazobactam against $S$. maltophilia was $1.75 \mathrm{mcg} / \mathrm{ml}$; $\mathrm{MIC}_{50}$ and $\mathrm{MIC}_{90}$ were $1.5 \mathrm{mcg} / \mathrm{ml}$ and $>256 \mathrm{mcg} / \mathrm{ml}$, respectively. A specific clinical breakpoint for S. maltophilia has not been validated yet. However assuming a value of $\leq 4 \mathrm{mcg} / \mathrm{mL}, \quad 20 / 34 \quad(58.8 \%)$ of CF isolates were susceptible to ceftolozane/tazobactam. The percentage of isolates within the susceptible range for other antibiotics was as follows: $1 / 34(2.9 \%)$ for ceftazidime, $27 / 34(79.4 \%)$ for levofloxacin, 22/34 (64.7\%) for trimethoprim/sulfamethoxazole and 31/34 (91.2\%) for minocycline.

A. xylosoxidans and B. cenocepacia were resistant to ceftolozane/tazobactam (median MICs were $32 \mathrm{mcg} / \mathrm{ml}$ and $>256 \mathrm{mcg} / \mathrm{ml}$ for $A$. xylosoxidans and $B$. cenocepacia, respectively) as well as to all the others antimicrobial comparators

\section{DISCUSSION}


This study demonstrates that ceftolozane/tazobactam has the lowest percentage of in-vitro antimicrobial resistances against $P$. aeruginosa within the beta-lactam group. In $P$. aeruginosa strains ceftolozane/tazobactam resistance was less than for the majority of antimicrobials, including aminoglycosides and fluoroquinolones. Only colistin had a better in vitro performance. Ceftolozane/tazobactam is a new antipseudomonal compound and not yet widely used in CF. A recent case report demonstrated the first successful use of ceftolozane/tazobactam to treat an acute respiratory exacerbation of CF caused by MDR $P$. aeruginosa $[11,12]$. Our CF related-data is in agreement with previously published non-CF data [13], demonstrating that ceftolozane/tazobactam was active in the majority of meropenemresistant $P$. aeruginosa isolates.

A subanalysis for $P$. aeruginosa showed that MICs for ceftolozane/tazobactam were higher as isolates became resistant to one, two or more antimicrobial classes. All isolates resistant to all antimicrobial classes, including colistin, were also resistant to ceftolozane/tazobactam. These results suggest that resistance mechanisms for ceftolozane/tazobactam may already exist in MDR isolates and such mechanisms are probably shared with other antibiotics.

Antimicrobial resistance to common beta-lactams in S. maltophilia was consistent with data published for non-CF patients [14]. However, it is encouraging to note ceftolozane/tazobactam performed well against Stenotrophomonas with almost 60\% of isolates susceptible at a surrogated clinical breakpoint. In contrast ceftolozane/tazobactam had little in vitro effect against other NF-GNB such as $B$. cenocepacia and $A$. xylosoxidans. 
This is the largest sample of NF-GNB tested for ceftolozane/tazobactam and the data suggests that it has a role in the treatment of $P$. aeruginosa resistant to commonly used beta-lactams and S. maltophilia isolates. Additionally, this is the first study to perform antibiotic susceptibility testing of ceftolozane/tazobactam on B. cenocepacia isolates confirming the highly resistant pattern of this group of bacteria.

The most notable limitation of this study is the data was generated from a single centre. Further large-scale studies including clinical NF-GNB isolates from different centres/countries are warranted to further corroborate our findings.

This collection of isolates dates back to the period 2001-2010 and the percentage of resistant pathogens may have changed since this epoch.

Our results should be interpreted under the understanding that :1) the susceptibility profiles studied here may not reflect the in vivo activity in patients with $C F$, since microorganisms tested may be in a biofilm-mode of growth and we are not able to report any differences between mucous versus non-mucous strains; 2) the current clinical breakpoint for ceftolozane/tazobactam is calculated for abdominal or complicated urinary tract infections in non-CF population. A definite breakpoint for $P$. aeruginosa isolated from CF sputum as well as other non-fermenting pathogens has not been determined as yet.

Lastly, although microdiffusion is usually preferred to test MIC for colistin, in this study MIC values have been obtained following disc diffusion methodology.

In conclusion, ceftolozane/tazobactam showed excellent in vitro activity against $P$. aeruginosa from CF clinical isolates. This antibiotic is a potential therapeutic option 
when presented with challenging MDR $P$. aeruginosa and $S$. maltophilia exacerbations. Further clinical experience and trials in CF are required to determine the place of this antimicrobial in clinical practice.

\section{DECLARATIONS}

Funding: Author AG was funded by a grant from the Italian Respiratory Society. The funding Society did not contribute to the content of this manuscript.

Competing Interests: None.

Ethical Approval: Not applicable

\section{ACKNOWLEDGEMENTS}

The authors gratefully acknowledge the gift of E-test strips for ceftolozane/tazobactam from Merck UK Ltd. 


\section{REFERENCES}

1) Elborn JS. Cystic fibrosis. Lancet. 2016 Nov 19;388(10059):2519-2531. doi:

10.1016/S0140-6736(16)00576-6. Epub 2016 Apr 29. Review. PubMed PMID: 27140670 .

2) Burgel PR, Bellis G, Olesen HV, Viviani L, Zolin A, Blasi F, Elborn JS; ERS/ECFS Task Force on Provision of Care for Adults with Cystic Fibrosis in Europe. Future trends in cystic fibrosis demography in 34 European countries. Eur Respir J. 2015 Jul;46(1):133-41. doi: 10.1183/09031936.00196314. Epub 2015 Mar 18. PubMed PMID: 25792639.3

3) Pitt TL, Sparrow M, Warner M, Stefanidou M. Survey of resistance of Pseudomonas aeruginosa from UK patients with cystic fibrosis to six commonly prescribed antimicrobial agents. Thorax 2003;58:794-6.

4) Mustafa MH, Chalhoub H, Denis O, Deplano A, Vergison A, Rodriguez-Villalobos H, Tunney MM, Elborn JS, Kahl BC, Traore H, Vanderbist F, Tulkens PM, Van Bambeke F. Antimicrobial Susceptibility of Pseudomonas aeruginosa Isolated from Cystic Fibrosis Patients in Northern Europe. Antimicrob Agents Chemother. 2016 Oct 21;60(11):6735-6741. doi: 10.1128/AAC.01046-16. Print 2016 Nov. PubMed PMID: 27572406; PubMed Central PMCID: PMC5075080.

5) European Medicines Agency, EMA/505055/2015

6) Zhanel GG, Chung P, Adam H, Zelenitsky S, Denisuik A, Schweizer F et al. Ceftolozane/tazobactam: a novel cephalosporin/beta-lactamase inhibitor combination with activity against multidrug-resistant gram-negative bacilli. Drugs (2014) 74: 31. doi:10.1007/s40265-013-0168-2.

7) Sader H, Farrell D, Castanheira M, Flamm RK, Jones RN. Antimicrobial activity of ceftolozane/tazobactam tested against Pseudomonas aeruginosa and 
Enterobacteriaceae with various resistance patterns isolated in European hospitals (2011-12). J Antimicrob Chemother 2014; 69 (10): 2713-2722. doi: 10.1093/jac/dku184.

8) https://www.merck.com/product/usa/pi_circulars/z/zerbaxa/zerbaxa_pi.pdf

9) EUCAST. Breakpoint Tables for Interpretation of MICs and Zone Diameters, Version 4.0, January 2014. http://www.eucast.org/clinical_breakpoints 10) Magiorakos, A.P. et al. Multidrug-resistant, extensively drug-resistant and pandrug-resistant bacteria: an international expert proposal for interim standard definitions for acquired resistance. Clin Microbiol Infect 2012; 18: 268-281

11) Grohs P, Taieb G, Morand P, Kaibi I, Podglajen I, Lavollay M, et al. 2017. In vitro activity of ceftolozanetazobactam against multidrug-resistant nonfermenting Gramnegative bacilli isolated from patients with cystic fibrosis. Antimicrob Agents Chemother 61:e02688-16. https:// doi.org/10.1128/AAC.02688-16.

12) Vickery SB, McClain D, Wargo KA. Successful Use of Ceftolozane-Tazobactam to Treat a Pulmonary Exacerbation of Cystic Fibrosis Caused by Multidrug-Resistant Pseudomonas aeruginosa. Pharmacotherapy. 2016 Oct;36(10):e154-e159.

13) Buehrle DJ, Shields RK, Chen L, Hao B, Press EG, Alkrouk A et al (2016). Evaluation of the in vitro activity of ceftazidime-avibactam and ceftolozanetazobactam against meropenemresistant Pseudomonas aeruginosa isolates. Antimicrob Agents Chemother 60:3227-3231. doi:10.1128/AAC.02969-15.

14) Wei C, Ni W, Cai X, Zhao J, Cui J (2016) Evaluation of Trimethoprim/Sulfamethoxazole (SXT), Minocycline, Tigecycline, Moxifloxacin, and Ceftazidime Alone and in Combinations for SXTSusceptible and SXT-Resistant Stenotrophomonas maltophilia by In Vitro Time-Kill Experiments. PLoS ONE 11(3): e0152132. doi:10.1371/journal. pone.0152132 


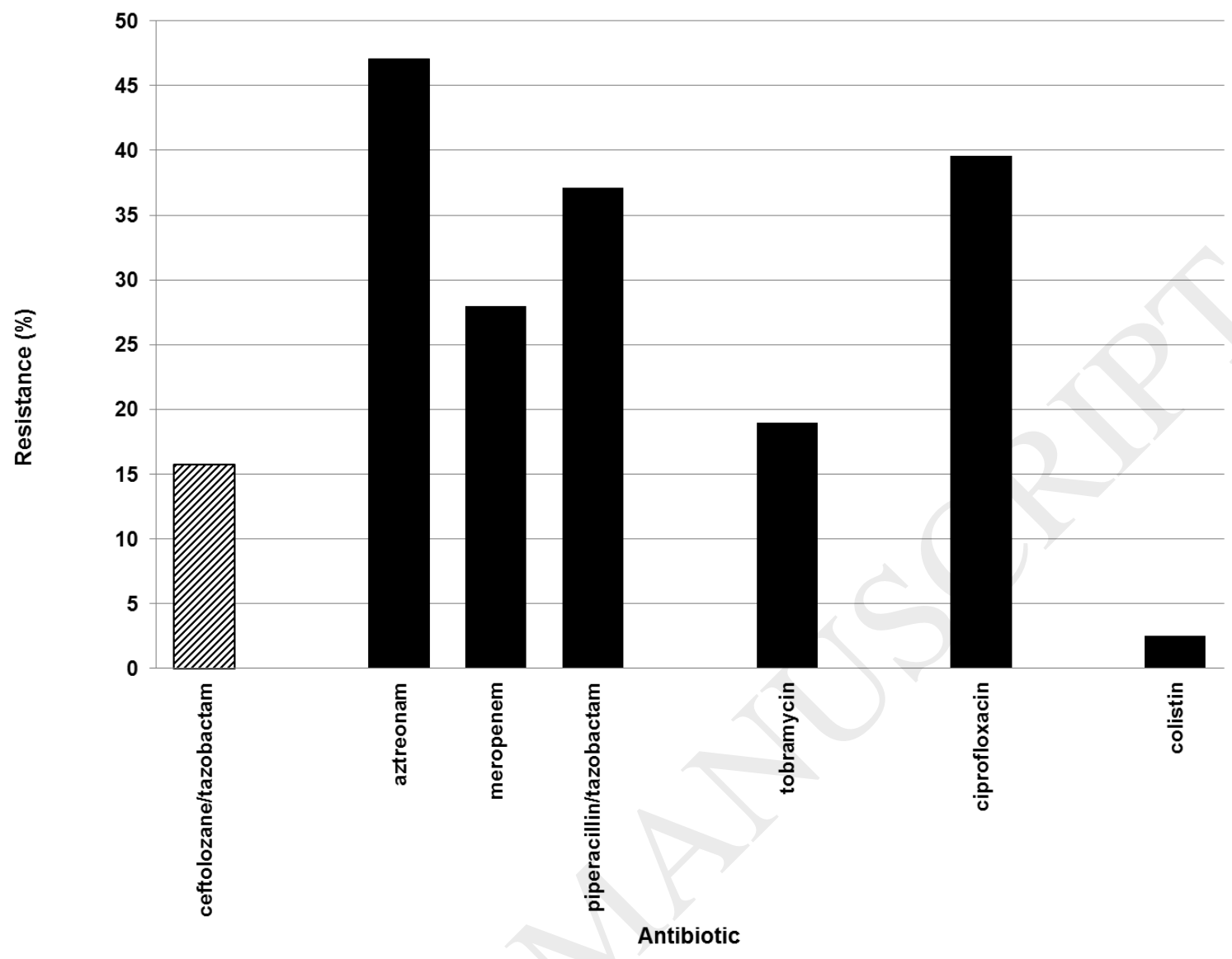

Figure 1: Percentage of Pseudomonas aeruginosa isolates resistant to ceftolozane/tazobactam and other commonly used anti-pseudomonal antibiotics. 
Table 1 - Antibiotic susceptibility of Pseudomonas aeruginosa isolates to ceftolozane/tazobactam according to resistance to other antimicrobials

\begin{tabular}{|l|l|}
\hline Pseudomonas aeruginosa isolates & MIC (range) $[\mathbf{m c g} / \mathbf{m L}]$ \\
\hline MDR Pseudomonas isolates $(\mathrm{n}=29)$ & $1.5(0.75->256)$ \\
XDR Pseudomonas isolates $(\mathrm{n}=22)$ & $3.5(0.75->256)$ \\
\hline Pan-Resistant Pseudomonas isolates $(\mathrm{n}=3)$ & $256(>256->256)$ \\
\hline
\end{tabular}

